\title{
Processo de transição para vivência com estomias intestinais de eliminação: repercussões na imagem corporal
}

\section{Transition process to experience with elimination intestinal stoma: repercussions on body image}

\section{Proceso de transición para vivir con eliminación de ostomía intestinal: repercusiones en la imagen corporal}

Nara Reisdorfer" ${ }^{*}$, Melissa Orlandi Honório Locks', Juliana Balbinot Reis Girondi', Lúcia Nazareth Amante1, Magali Schutz Corrêa

ORCID IDS

Reisdorfer N (D) https://orcid.org/ 0000-0002-5637-8649

Locks MOH (iD https://orcid.org/ 0000-0003-0972-2053

Girondi JBR (D) https://orcid.org/ 000-0002-37634176

Amante LN (D) https://orcid.org/ 0000-0002-5440-2094

Corrêa MS (D) https://orcid.org/ 000-0001-8289-0200
COMO CITAR

Reisdorfer N, Locks MOH, Girondi JBR, Amante LN, Corrêa MS. Processo de transição para vivência com estomias intestinais de eliminação: repercussões na imagem corporal. ESTIMA, Braz. J. Enterostomal Ther., 16: e1219. https://doi.org/10.30886/estima. v16.683_PT

\section{RESUMO}

Objetivo: Conhecer o processo de transição e adaptação para a vivência com estomia intestinal de eliminação. Métodos: estudo misto, descritivo-exploratório, realizado entre maio e julho de 2018 por meio de entrevista semiestruturada e aplicação da escala de imagem corporal com 13 pessoas com estomia, no retorno pós-operatório em um hospital federal no sul do país. A análise dos dados deu-se por categorias temáticas e análise descritiva simples. Resultados: os dados apontaram paridade entre os sexos, idade média de 60,5 anos, maioria casada, com baixo grau de instrução e afastada das atividades laborais. Causas principais geradoras do estomia foram as neoplasias, as estomias com mais de seis meses e as temporárias. As complicações mais identificadas foram prolapso de alça intestinal e dermatites. As mudanças mais significativas ocorreram no padrão alimentar, vestuário, comportamento social e reflexos na imagem corporal. A subescala corpo pré-mórbido teve média de 22,23 pontos e a subescala corpo mórbido teve média de 15,15 pontos. Conclusão: A condição de ser uma pessoa com estomia acarreta impacto na maneira como o indivíduo vê seu corpo. Ressalta-se a importância de que os indivíduos com risco de má adaptação sejam identificados e abordados o mais precocemente possível.

DESCRITORES: Estomia; Imagem corporal; Enfermagem; Estomaterapia

1 Universidade Federal de Santa Catarina - Departamento de Ciências da Saúde - Florianópolis/SC - Brasil.

¿Universidade Federal de Santa Catarina - Hospital Universitário Polydoro Ernani de São Thiago - Florianópolis/SC - Brasil.

*Autor correspondente: nara.reisdorfer@hotmail.com

Recebido: 18 Dez 2018 | Aceito: 12 Jun 2019 


\begin{abstract}
Objective: to know the process of transition and adaptation to the experience with elimination intestinal stoma. Methods: a descriptiveexploratory, mixed study conducted between May and July 2018 through a semi-structured interview and application of the body image scale with 13 people with a stoma, at the postoperative return in a federal hospital in the south of the country. The data analysis was by thematic categories and simple descriptive analysis. Results: The data showed a parity between the genders, mean age of 60.5 years, most parts married, with low education level, and away from work activities. The leading generator causes of stoma were neoplasias, stomas with more than six months, and temporary. The most frequently identified complications were intestinal loop prolapse and dermatitis. The most significant changes occurred in the food pattern, clothing, social behavior, and body image reflexes. The premorbid body subscale had an average of 22.23 points, and the subscale morbid body had an average of 15.15 points. Conclusion: The condition of being a person with a stoma has an impact on the way the individual sees their body. It is essential to highlight that individuals at risk of maladaptation are identified and addressed as early as possible.
\end{abstract}

DESCRIPTORS: Stoma; Body image; Nursing; Stomatherapy.

\title{
RESUMEN:
}

Objetivo: Conocer el proceso de transición y adaptación para la vivencia con eliminación de ostomía intestinal. Métodos: Un estudio mixto descriptivo y exploratorio, realizado entre mayo y julio de 2018 a través de entrevistas semiestructuradas y aplicando la escala de imagen corporal con 13 personas con ostomía, en el retorno postoperatorio en un hospital federal en el sur del país. Los datos fueron analizados por categorías temáticas y análisis descriptivo simple. Resultados: Los datos mostraron paridad de género, edad promedio de 60.5 años, mayormente casados, con baja educación y actividades fuera del trabajo. Las principales causas de la ostomía fueron neoplasias, ostomías mayores de seis meses y temporales. Las complicaciones más identificadas fueron prolapso de asa intestinal y dermatitis. Los cambios más significativos ocurrieron en los patrones dietéticos, la ropa, el comportamiento social y los reflejos de la imagen corporal. La subescala del cuerpo pre-mórbido promedió 22.23 puntos y la subescala del cuerpo mórbido promedió 15.15 puntos. Conclusión: Ser una persona con una ostomía tiene un impacto en la forma en que un individuo ve su cuerpo. La importancia de las personas en riesgo de mala adaptación debe identificarse y abordarse lo antes posible.

DESCRIPTORES: Ostomía; Imagen corporal; Enfermería; Estomaterapia.

\section{INTRODUÇÃO}

As estomias intestinais de eliminação têm a finalidade de desviar o trânsito intestinal de forma temporária ou definitiva para fins curativos ou paliativos quando alguma parte do intestino apresenta disfunção. Dentre as indicações estão as neoplasias do cólon e reto, diverticulite, perfuração intestinal, oclusão intestinal, fístulas, doença inflamatória do intestino e polipose adenomatosa ${ }^{1}$.

O processo de confecção de uma estomia, seja ela em qualquer porção do intestino, temporária ou definitiva, requer cuidado especializado de enfermagem. As pessoas que necessitam de tal procedimento têm sua perspectiva de vida alterada, pelo medo do ato cirúrgico, pelas dúvidas e anseios da vida após esse, além das mudanças na imagem corporal devidas à presença da estomia e da bolsa coletora. Associadas a isso, ocorrem mudanças nos hábitos alimentares e de higiene, além da necessidade de adaptação devido ao uso de alguns equipamentos, o que pode levar a alterações de autoestima, da sexualidade e, algumas vezes, isolamento social $^{2}$.
A imagem corporal é a percepção que a pessoa tem do seu próprio corpo, a figura criada na mente e o modo com que essa se apresenta para cada sujeito, variando ao longo da vida, podendo ser influenciada pelo contexto no qual a pessoa se encontra. Refere-se à figura que se tem na mente, de tamanho, imagem e forma, expressando também sentimentos relacionados a essas características ${ }^{3}$.

A enfermagem, munida de conhecimentos técnicos e científicos, é capaz de preparar a pessoa para o ato cirúrgico, com esclarecimento de dúvidas e suporte às demandas emocionais, além de todos os cuidados técnicos. Pode ainda auxiliar no trans-operatório e na reabilitação dessa pessoa, com suporte e encaminhamentos no âmbito dos direitos sociais, além de potencializar o autocuidado com medidas educativas a fim de proporcionar melhora na qualidade de vida $(\mathrm{QV})$ dessa população ${ }^{4}$.

Embora as pessoas com estomia possam ter características em comum, observam-se necessidades individualizadas, subjetivas, como decorrentes de inseguranças, dificuldade de resiliência e frágil rede de apoio. A pesquisa justifica-se, pois, conhecer a população que passa por tal processo possibilita 
aos profissionais planejar o cuidado fundamentado nesses dados, bem como ações de educação em saúde e capacitação dos profissionais da rede. O foco é a melhoria da assistência à saúde e, consequentemente, da QV dos indivíduos, respeitando sua individualidade. Desse modo, a pergunta norteadora do estudo foi: "Como ocorre o processo de transição e adaptação para a vivência com estomia intestinal de eliminação?”. O objetivo traçado foi conhecer o processo de transição e adaptação para a vivência com estomia intestinal de eliminação.

\section{MÉTODOS}

Trata-se de estudo de caráter misto, do tipo descritivoexploratório. O estudo foi desenvolvido em um hospital universitário localizado na região sul do Brasil. A instituição é totalmente pública, concebida na perspectiva do trinômio ensino, pesquisa e extensão, que atende à comunidade local e $18^{\text {a }}$ regional de saúde do estado de Santa Catarina.

Os participantes do estudo foram adultos com estomias no mínimo há três meses, usuários do serviço de atendimento ambulatorial da equipe de proctologia, abordados em seu retorno para acompanhamento pós-cirúrgico nos meses de maio a julho de 2018. O convite para participação na pesquisa ocorreu no retorno, no momento em que o possível participante aguardava a consulta médica. Mediante aceite, a entrevista ocorreu no mesmo dia e em sala privativa no próprio ambulatório. O estudo respeitou todos os preceitos ético da Resolução no 466/20125 , sendo aprovada pelo Comitê de Ética em Pesquisa com Seres Humanos sob parecer no 1.788.494.

Para coleta de dados, realizou-se entrevista semiestruturada com questões abertas e fechadas. Para identificar o perfil sociodemográfico, utilizaram-se as variáveis demográficas sexo e faixa etária. Além dessas, buscou-se conhecer características da confecção da estomia e o processo de transição da adaptação e do autocuidado. As entrevistas foram gravadas e posteriormente transcritas na íntegra. Após essa técnica de coleta, foi também aplicada a escala de imagem corporal "Como me relaciono com o meu corpo".

As respostas foram obtidas por meio de uma escala contendo 14 itens, do tipo Likert, na qual, sob a forma de afirmações, investiga-se a concordância em relação a alguns aspectos do corpo que os clientes consideram importantes, como se relacionam com o corpo e como valorizam sua aparência. Conta-se na ordem crescente: "não concordo" = 1; "concordo pouco" = 2; "concordo moderadamente" = 3; "concordo bastante" $=4$. Os scores são obtidos pelo somatório dos sete itens, dando origem a um score que varia entre 7 e 28 em cada uma das escalas, sendo que quanto maior o score obtido, melhor será a relação com a imagem corporal.

A análise dos dados qualitativos se deu por análise temática ${ }^{7}$ que consiste em três fases: a pré-análise, a organização do que vai ser analisado; a exploração do material por meio de várias leituras; e o tratamento dos resultados, permitindo destaque para as informações obtidas. Os dados quantitativos da escala de imagem corporal foram analisados por meio de estatística descritiva que envolve a organização, o resumo e a representação dos dados.

\section{RESULTADOS}

O estudo contou com 13 participantes procedentes da região metropolitana de Florianópolis, estado de Santa Catarina. Observou-se paridade entre os sexos, e os participantes, em sua maioria, tinham idade média de 60,5 anos, eram casados e com baixo grau de instrução, sendo que oito tinham até oito anos de estudo. Apesar de oito dos participantes terem menos de 60 anos, apenas um está inserido no mercado de trabalho, um autônomo sem exercer a profissão no momento; os demais participantes se encontram aposentados.

Com relação à causa geradora da estomia, houve grande destaque para as neoplasias (69\%), sendo que a maioria dos participantes se encontrava com estomia há mais de seis meses (46\%), apesar de 10 com estomias temporárias. O principal tipo de estomia foram as colostomias (69\%), prevalecendo as de colón descendente; as complicações mais comuns foram prolapso de alça intestinal e dermatite periestoma, sendo que quatro participantes apresentaram ambas as complicações.

A análise dos dados qualitativos permitiu a construção de duas categorias: processo de transição, do diagnóstico ao convívio com a estomia; e estomia de eliminação: reflexos na imagem corporal, convívio social e trabalho.

\section{Processo de transição: do diagnóstico ao convívio com a estomia}

O momento do diagnóstico de uma condição clínica com necessidade de cirurgia de grande porte e potencialmente 
mutiladora pode causar grande impacto na vida das pessoas. Observou-se, no estudo, que a notícia é encarada inicialmente de forma negativa pela maioria dos participantes, porém alguns demostraram compreendê-la como possibilidade de manutenção da vida.

"Quando o médico falou que precisava colocar eu chorei, soube na hora que estava indo para cirurgia. Eu chorei e pensei: meu Deus, uma coisa pendurada na barriga. Se a bolsinha for para a necessidade que eu tive, é a maior benção divina ter a possibilidade de colocar bolsinha. Se não fosse essa bolsinha, eu não estaria mais aqui." (P6)

"Quando recebi o resultado do câncer, aí o médico já disse que tinha que operar. Eu até fui meio arredio, não queria colocar a bolsinha. Isso aqui para mim é um transtorno, não dá para admitir ter uma bolsa, tu andar com as fezes."(P13)

Em sua maioria, nove dos participantes tiveram diagnóstico de neoplasia, agravo esse que carrega uma carga cultural de sofrimento muito grande. Associado ao impacto desse diagnóstico e acompanhado pelo processo de assimilação da necessidade cirúrgica com confecção da estomia e recuperação pós-cirúrgica, esses precisam, ainda, passar pelo tratamento quimioterápico. Essa preocupação foi identificada em alguns participantes, como descrito a seguir

“Claro, todos vamos morrer, isso é certeza, a gente já nasce sabendo. Mas o câncer te indica uma realidade que eu não imaginava antes. Realmente eu vou morrer e já estou com data de validade. Falou em câncer as pessoas pensam: esse aí já foi.” (P4)

Quando questionados quanto ao preparo e orientação no pré-operatório, dos participantes do estudo, 11 foram informados antes da cirurgia que necessitariam de estomia. Os outros dois realizaram a cirurgia de forma emergencial e não tiveram essa informação, sendo comunicada ao familiar.

No espaço hospitalar, o paciente e seus familiares têm o primeiro contato com a estomia. As primeiras limpezas e trocas do equipamento coletor ocorrem nesse local, onde a equipe de enfermagem atua como facilitadora no processo de autocuidado. Ao serem questionados quanto ao ensino prestado pela equipe de enfermagem, todos os participantes relataram ter recebido, sendo que oito classificaram-no como muito adequado, quatro como relativamente adequado e um avaliou como pouco adequado.

"Da enfermagem a gente recebeu toda a instrução antes de receber alta, todo o processo de troca ela já ensinava, foi muito adequada a informação, tudo que elas falaram deu certo." (P12)

Ainda que exista a rotina estabelecida quanto à orientação e preparo antes da alta hospitalar, percebe-se que, devido ao excesso de informações, muitas não são absorvidas. Surge, então, a orientação pré-operatória como alternativa viável.

"Olha, algumas coisas sim, mas eu ainda tenho algumas dificuldades, talvez eles tenham até falado, mas é muita gente chegando lá, e vai nutricionista, e isso e aquilo, é muita informação, às vezes não consegue captar aquilo que realmente precisava. Às vezes é tão rápido que a pessoa não consegue assimilar. Se conseguir fazer isso já antes da cirurgia, a pessoa tem mais tempo e já começa a se preparar.”(P13).

Outro aspecto identificado foram as dificuldades verbalizadas na transição do hospital para casa, sendo relatado como um momento de grande mudança na estrutura familiar. A família se mostrou como grande aliada nesse processo de adaptação e vivência com a estomia. Cada participante e sua organização familiar são únicos, mas, em geral, observou-se a permanência do cônjuge como cuidador principal, pois esse auxiliava nos cuidados diretos com a estomia e também nas atividades de vida diária.

"Se não fosse minha família, se não fosse minha mulher e minha filha, eu não sei o que seria de mim, essa é a verdade. Eles são tudo para mim, não tem outra definição.” (P4)

"Ainda bem que meu marido é uma pessoa bem paciente, ele entende tudo, ele fica no hospital comigo, mas às vezes eu fico pensando, meu Deus, se fosse outro homem já tinha dado no pé. Meu marido não trabalha mais para cuidar de mim.”(P6)

Ao chegar no domicílio, os participantes relataram ter se deparado com algumas dificuldades no cuidado com a estomia e seus equipamentos, necessitando de ajuda de familiares em alguns dos processos, normalmente referente à troca da bolsa. Outros relatam total independência no 
manejo técnico da estomia e equipamentos adjuvantes. Observou-se a adaptação mais favorável dos participantes que apresentaram complicações pós-cirúrgicas com internação de longa duração. Alguns apresentaram deiscência de sutura ou lesões por pressão com necessidade de reintervenção cirúrgica ou curativos diários.

"Saí do hospital com uma escara muito grande, três meses de cama aqui no hospital deu escara, e custou a sarar [...] lavar normalmente sou eu quem lava, e a troca dela é quando começa a descolar, então quando há necessidade de lavar, fazer a higiene, eu vou ali e faço. Dificuldade não tive muito, aprendi a limpar fácil.” (P1)

"As maiores dificuldades é que no começo eu queria caminhar, aí o estoma saiu para fora e a gente teve que vir parar na emergência [...] estou seguindo a vida normal, me adaptei bem rápido, fiz tudo logo sozinha. Eu limpo de hora em hora para não ter risco de descolar ou de estourar, é normal, já acostumei." (P9)

Os participantes experienciaram diferentes realidades no processo de adaptação. Boa parte com apoio mais próximo dos familiares nas adaptações das atividades de vida diária, no cuidado com a estomia, além do apoio emocional e financeiro. Uma série de mudanças nos hábitos de vida foi elencada, dentre elas o processo alimentar com vistas à modulação da consistência das fezes e diminuição da produção de gases. Mudanças também no modelo de roupas, optando por peças mais largas, com intuito de disfarçar o equipamento coletor. Alguns participantes relataram limitar-se ao ambiente domiciliar, saindo apenas quando necessário, diminuindo viagens, idas à praia, igrejas e casa de familiares e amigos, em decorrência da imprevisibilidade das eliminações.

“Teve muita mudança, eu não dirigi mais, eu não vou dirigir com isso aqui balançando. Não viajei mais, ia para minha casa de praia, não fui mais.” (P1)

"A questão da alimentação também no início, e a gente fica muito triste por deixar algumas coisas de lado [...] agora eu vou pouco na igreja, que eu tinha até cargo lá na igreja, sentava todos os obreiros juntos, perto, aí eu passei a ir de vez em quando, só que eu não como no dia, aí fico sentado lá para trás, perto da porta.” (P3)
“Outra dificuldade é que em casa a gente dá um jeito de lavar sempre, mas quando vai sair não tenho um local adequado para lavar essa bolsinha.” (P5)

"Eu tive que comprar roupa larga para não aparecer muito, eu não me acostumei não.” (P6)

\section{Estomia de eliminação intestinal: reflexos na imagem corporal, convívio social e trabalho}

O processo de adaptação e aceitação de uma estomia de eliminação varia de pessoa para pessoa, influenciado pela cultura, conhecimento prévio, medos, expectativas, complicações e rede de apoio. Além disso, a questão de gênero surgiu nas entrevistas como um dos fatores influenciadores nesse processo. Alguns participantes mostraram-se mais abatidos e com relutância em manusear os equipamentos coletores, tanto para limpeza quanto para troca, por dificuldade de aceitação, de se ver como uma pessoa com estomia.

\begin{abstract}
"Eu me olho meio escondido, quando eu tiro a camisa e vejo aquilo ali na frente do espelho, eu não fico, vou me esconder." (P2)
"Mudou tudo, assim eu não vivo, todo mundo diz que é vida normal, mas não é não. Pode ser que seja para outras pessoas, mas para mim não. Conheci um amigo que tinha isso, mas ele vivia, ele ia para o banco, ele bebia cerveja, foi um incômodo, mas para a gente, mulher, eu acho que é sempre pior." (P6)

A maior parte dos participantes relatou que a estomia de eliminação interferiu no convívio social, seja pela imprevisibilidade da eliminação do efluente, seja pela liberação de gases, barulho e odor, relatando que mesmo com o disco de carvão ativado ainda é possível sentir o odor, o que acaba causando constrangimentos.

\footnotetext{
"Não pode nem sair, se bem que eu saio pouco, procuro evitar muita aglomeração por causa de gases, essas coisas são muito constrangedoras.” (P3)

“Querendo ou não, por mais que tu disfarce, sempre vai ter uma brotoeja aqui. As pessoas te olham, tu estás sentado
} 
ao lado de alguém no posto de saúde, que seja, isso daqui faz barulho, fica difícil o social." (P4)

Além disso, relataram o preconceito sofrido em decorrência da estomia, fator que contribuiu para o afastamento ainda maior desses participantes do convívio social, buscando, em alguns casos, aproximar-se cada vez mais da família, para suprir a necessidade de socialização. Outros, por sua vez, buscaram pela independência no cuidado com estomia, relatando sentir-se um peso para os familiares ou infantilizados, comparando a limpeza do equipamento coletor com a troca de fraldas em bebês.

"Para todo mundo que eu conheci na internet, eu falava tudo que eu passei, que eu estava com cirrose por hepatite e que eu estava com as bolsinhas de colostomia, aí me bloqueavam. Tinha gente que deixava de falar, não falava mais nada, ficava mudo, preconceito assim enorme." (P10)

"Sofro bastante constrangimento, um dia acharam que eu estava armado, mas era só a bolsinha." (P11)

“É triste, é ruim, porque, pensa bem, tu estás voltando a ser criança, tu ficas depende, tu és dependente total das pessoas e isso faz muito mal. É difícil. Minha filha está ali comigo, quando precisa me levam, só que tudo é difícil, ela deixou de trabalhar para estar comigo aqui, isso machuca também a mim.” (P13)

Os participantes acabaram se afastando de quase todo convívio social, até de suas atividades laborais. Apenas um dos participantes mantinha-se ativo no campo de trabalho.

"Meus afazeres de casa não fiz mais, estava sempre fazendo alguma coisa, sou homem que não para, gosto de estar me movimentando, agora estou mais parado, fui obrigado.”(P1)

"Olha, hoje eu estou como aposentado por invalidez, mas eu sou engenheiro. Eu tinha uma empresa, tive que fechar a empresa,é dolorido, porque tu chegas numa situação que me sinto inválido, como se não tivesse capacidade de fazer mais nada."(P13)

A vivência com a estomia, os constrangimentos, o distanciamento das atividades de lazer e laborais acabaram repercutindo na percepção da imagem corporal dos participantes. Assim como alguns participantes relataram adaptar-se bem à estomia e aos equipamentos, relatando nenhuma alteração da imagem corporal, outros relataram se sentir incompletos e incapazes de se olhar após sua confecção, preferindo o óbito à possibilidade de passar o restante da vida com a estomia.

“O doutor disse que é perigoso fazer outra cirurgia, que são quase quatro horas de cirurgia, tem todo um risco, aquela coisa toda, mas eu prefiro correr esse risco do que viver minha vida com isso aqui." (P4)

"Eu quero fazer a cirurgia, tomara que o médico não diga para mim que é para sempre, senão eu cometo suicídio, eu vou ficar muito triste." (P10)

Após a aplicação da escala de imagem corporal, foi possível identificar algumas questões relacionadas à percepção da imagem dos participantes do estudo. A subescala da imagem corporal em relação ao corpo pré-mórbido apresentava pontuação máxima de 28 pontos e mínima de 7 pontos, com média de 22,23 pontos. A subescala "corpo mórbido" apresentava pontuação máxima de 28 pontos e mínima de 7, com média de 15,15 pontos (Tabelas 1 e 2).

Observou-se que as mulheres procuram disfarçar mais aspectos do seu corpo que não lhes agradam, sentem-se menos atraentes e fisicamente mais inibidas, porém os números não foram estatisticamente significativos. Houve relatos de mudanças na vida sexual por dificuldade de aceitação e compreensão do novo corpo.

"A vida toda mudou, até o casamento, sexo nem pensar, eu não fico à vontade, estou doida para tirar essa bolsa e voltar ao normal.” (P6)

Para lidar com essas questões, observou-se que as principais estratégias de enfrentamento relatadas foram a presença da família, religiosidade e esperança da reconstrução de trânsito intestinal. Os participantes acabam depositando suas expectativas em uma possível reconstrução de trânsito.

"Minhas estratégias são a força e a coragem, pedir força a Deus e coragem. É o jeito.” (P6)

"Eu estou confiante que eles vão reverter tudo isso, que vou me internar e vão tirar. A minha estratégia é esperar mais uma semana e o médico falar que vai me internar e fazer reversão. A estratégia é a esperança.” (P10) 
Tabela 1. Respostas de pessoas atendidas no ambulatório do hospital universitário referente à subescala de imagem em relação ao corpo pré-mórbido. Florianópolis/SC, 2018.

\begin{tabular}{|c|c|c|c|c|}
\hline Item & $\begin{array}{c}\text { Não } \\
\text { concordo }\end{array}$ & $\begin{array}{c}\text { Concordo } \\
\text { pouco }\end{array}$ & $\begin{array}{l}\text { Concordo } \\
\text { moderado }\end{array}$ & $\begin{array}{l}\text { Concordo } \\
\text { bastante }\end{array}$ \\
\hline Considero que o meu corpo é uma expressão do "ser masculino/ feminino" & 0 & 1 & 2 & 10 \\
\hline O corpo assume mais importância numa relação entre o homem e a mulher & 3 & 2 & 3 & 5 \\
\hline Sinto-me capaz de afirmar que gosto do meu corpo & 3 & 1 & 1 & 8 \\
\hline A(o) minha(meu) parceira(o) gosta do meu corpo & 2 & 0 & 2 & 9 \\
\hline Olho com agrado para o meu corpo. & 5 & 1 & 0 & 7 \\
\hline Valorizo a imagem do meu corpo. & 1 & 0 & 1 & 11 \\
\hline Procuro disfarçar aspectos do meu corpo que não me agradam. & 4 & 0 & 2 & 7 \\
\hline
\end{tabular}

Fonte: dados da pesquisa, 2018.

Tabela 2. Respostas de pessoas atendidas no ambulatório do hospital universitário referente à subescala de imagem em relação ao corpo mórbido. Florianópolis/SC, 2018.

\begin{tabular}{|c|c|c|c|c|}
\hline Item & $\begin{array}{l}\text { Não } \\
\text { concordo }\end{array}$ & $\begin{array}{l}\text { Concordo } \\
\text { pouco }\end{array}$ & $\begin{array}{l}\text { Concordo } \\
\text { moderado }\end{array}$ & $\begin{array}{l}\text { Concordo } \\
\text { bastante }\end{array}$ \\
\hline Tenho me sentido inibido (a) em relação à minha aparência. & 3 & 0 & 3 & 7 \\
\hline $\begin{array}{l}\text { Sinto me menos atraente fisicamente como resultado da minha doença } \\
\text { e/ou tratamento. }\end{array}$ & 3 & 1 & 2 & 7 \\
\hline $\begin{array}{l}\text { Tenho me sentido menos masculino/feminina, como resultado da doença ou } \\
\text { tratamento }\end{array}$ & 6 & 0 & 3 & 4 \\
\hline Considero que tem sido difícil olhar para mim quando estou nu(a). & 5 & 0 & 4 & 4 \\
\hline $\begin{array}{l}\text { Tenho-me sentido menos atraente sexualmente como resultado da minha } \\
\text { doença ou tratamento }\end{array}$ & 3 & 1 & 2 & 7 \\
\hline Sinto que a doença deixou o meu corpo incompleto. & 6 & 1 & 2 & 4 \\
\hline Tenho-me sentido insatisfeito com aparência da minha estomia & 1 & 0 & 3 & 9 \\
\hline
\end{tabular}

Fonte: dados da pesquisa, 2018.

A forma com que cada pessoa vivencia esse processo de adaptação é único e influenciada por inúmeras características, mas observou-se que o apoio familiar, em especial do cônjuge, a religiosidade e a esperança do procedimento cirúrgico reparador estiveram presentes na maior parte dos discursos.

\section{DISCUSSÃO}

No Brasil, não há uma publicação oficial, nos últimos 10 anos, com dados como perfil, incidência e prevalência relacionados à pessoa com estomia. Por esse motivo, optou-se por sistematizar os dados de alguns trabalhos brasileiros que analisam perfil de pessoas com estomia nos últimos cinco anos. Os achados na pesquisa realizada se assemelham aos da literatura dos últimos cinco anos.
A maior parte das pessoas com estomia é do sexo masculino $o^{8,-13}$, com idade superior a 60 anos ${ }^{8,9,12,13}$. O câncer foi o fator causal da cirurgia geradora do estomia ${ }^{8-14}$. Os tipos mais frequentes foram colostomias ${ }^{8-11}$ de caráter temporário ${ }^{13,14}$ e permanente ${ }^{8,10}$.

Estudo $^{13}$ mostrou que 53,6\% apresentaram complicações com a estomia, dermatite perístoma $(37,1 \%)$ e hérnia paracolostômica (17,5\%), em número menor o prolapso de alça intestinal $(2,1 \%)$, divergindo dos achados nesse estudo, no qual o prolapso se mostrou como principal intercorrência. No que se refere ao grau de instrução, a literatura mostra que há prevalência de nível de instrução mais baixo, sendo o nível fundamental incompleto ${ }^{10,13,14}$ também observado nesta pesquisa. Quanto à relação com o trabalho, observa-se grande afastamento das atividades laborais, sendo em sua maioria aposentados ou pensionistas, em geral com um salário mínimo ${ }^{10,11,14}$. Levando em consideração o perfil 
epidemiológico dos participantes do estudo, a maioria tem idade inferior a 60 anos e o retorno ao mercado de trabalho é um dos aspectos que devem ser considerados.

Quanto ao recebimento do diagnóstico médico, sabe-se que o impacto ante a qualquer situação de saúde crônica ou com necessidade cirúrgica mutiladora costuma ser bastante impactante. Ao tratar-se especificamente do diagnóstico de câncer, por si só esse gera tensões pelo encargo cultural que carrega. Quando vem associado à necessidade de confecção de estomia, tem potencial para gerar uma experiência traumatizante na vida das pessoas, tanto pelas limitações impostas pela condição, quanto pelas crenças e constrangimentos vivenciados.

O cuidado a essa população abrange inúmeras interfaces que dizem respeito não só às condições físicas e biológicas, mas também às alterações psicológicas nas relações intra e interpessoais vivenciadas no processo de transição. Quanto ao papel do enfermeiro no cuidado a essas pessoas, esse deve estar presente nas fases pré-, trans- e pós-operatória, além do acompanhamento na pós-alta em outros níveis de cuidado. A fase pré-operatória compreende o momento em que é tomada a decisão da intervenção cirúrgica até o encaminhamento para a sala de cirurgia. Nesse período, a atuação do enfermeiro é primordial, pois é importante realizar avaliação psicossocial e física com demarcação do possível local da estomia, com intuito de diminuir as dificuldades quanto ao enfrentamento, prevenir complicações e alcançar a melhor adaptação ${ }^{15}$.

Ressalta-se a importância de informar, no pré-operatório, a todas as pessoas que irão realizar cirurgia, sobre a possibilidade de confecção de estomia, com assinatura do termo de consentimento, além de prestar esclarecimentos para a família. A marcação da estomia deve ser realizada pelo enfermeiro estomaterapeuta, com vistas à escolha adequada do local, facilitando o autocuidado, a autonomia, a independência e a boa aderência do equipamento coletor. Estudo ${ }^{16}$ multicêntrico, retrospectivo, descritivo com 748 participantes mostrou que a taxa de complicações foi maior entre os quais o local da estomia não foi marcado, comparada com a daqueles cujo local de estomia foi marcado, 46 e 22,9\%, respectivamente.

O preparo da pessoa com estomia para alta deve ser o mais precoce possível, atentando para o processo de transição e autocuidado. Revisão ${ }^{17}$ que analisou 27 estudos nacionais e internacionais mostrou as principais ações realizadas pelo enfermeiro no preparo para a alta hospitalar: orientar quanto ao cuidado com a estomia; pele perístoma; equipamentos coletores; nutrição, hidratação e eliminação; apoio psicológico; e orientações quanto à atividade física e sexual. Dentre essas orientações, é necessário estimular o autocuidado, oferecer informações escritas sobre os cuidados, incluir o cuidador/familiar no ensino, utilizar tecnologias educativas compatíveis à realidade vivida por cada pessoa, orientar quanto ao vestuário apropriado e orientar sobre a utilização de medicamentos analgésicos em caso de dor.

Nesse processo de orientação, o enfermeiro precisa incentivar a autonomia da pessoa com estomia por meio do conhecimento prático com foco na minimização dos medos e das incertezas. O enfermeiro apresenta-se como o profissional que coordena, acolhe, cuida, apoia e aconselha o processo de transição, adaptação e auto aceitação ${ }^{18}$.

A transição do hospital para casa é geradora de sentimentos ambíguos. Nesse momento, aliam-se sentimentos como a alegria de retornar ao lar para junto dos seus e a insegurança com a nova condição de vida e ausência do profissional para realizar os cuidados. Na maioria das vezes, a família inicia os cuidados com a estomia no domicílio e, gradativamente, vai compartilhando esse cuidado com o paciente, de acordo com suas possibilidades. A família apresenta-se como fonte de apoio, acolhimento e cuidado, tanto no âmbito hospitalar, quanto no domicílio, e percorre todo itinerário terapêutico da pessoa com estomia. Isso permite que a pessoa se sinta segura, fomentando o sentimento de pertencer ao sistema familiar, pois essa família passa a ter novas necessidades de cuidado, sendo essencial que o enfermeiro e toda a equipe multiprofissional sejam capazes de identificar e acolher essas demandas ${ }^{19}$.

Além das mudanças físicas, os indivíduos com estomias intestinais de eliminação experienciam mudanças em suas rotinas, atividades de vida diária, vínculo empregatício e contatos sociais. Verificou-se, entre os clientes, afastamento das atividades cotidianas, afazeres de casa, atividades de lazer e laborais. Esses fatores podem gerar ansiedade e outras demandas, levando em consideração a importância social e cultural do trabalho, visto como forma de dignificação do sujeito. Associam-se a isso a dependência financeira da aposentadoria, muitas vezes a necessidade de auxílio financeiro de familiares, a mudança da função social que exercia no seio familiar, bem como o peso de se considerar inapto.

A literatura corrobora os achados da pesquisa, demostrando que ter uma estomia afeta a integridade corporal, a capacidade funcional, o convívio social e a QV, gerando grande impacto no cotidiano ${ }^{20}$. Estudo ${ }^{11}$ com 
117 participantes mostrou que 51,3\% interromperam suas atividades laborais e $44,4 \%$ não retornaram, com afastamento pela previdência. Dos $48,7 \%$ que não interromperam as atividades laborais, 33,3\% eram aposentados, $13,6 \%$ exerciam atividade não remunerada e 1,7\% eram autônomos sem direito a afastamento.

Com relação ao convívio com a estomia, estudo transversal ${ }^{20}$ com 635 participantes demostrou que o tempo médio para se sentir confortável com a estomia foi de 214 dias. Com relação à adaptação, 39,6\% pessoas tiveram boa adaptação à estomia, 67,7\% tiveram dificuldade para o autocuidado, necessitaram de ajuda de familiares, e 50\% relataram alguma limitação para realizar atividades diárias.

Parte significativa dos participantes não tinha conhecimento prévio ou contato com pessoas com estomias e não tinha concepção do que é uma estomia, as dimensões dos equipamentos coletores e o processo de eliminação do efluente. $\mathrm{O}$ estranhamento ante o novo e desconhecido corpo repercute de diferentes formas nas pessoas com estomias, podendo influenciar na forma com que essa se vê e se autoconceitua.

Os participantes relatam insegurança, constrangimento e discriminação com a estomia diante da sociedade e das pessoas que os circundam. A nova condição é vista como mutiladora, alterando a ideia de corpo perfeito imposto pela sociedade contemporânea. A marginalização e o preconceito por parte dos que se consideram nos padrões acabam por afastar ainda mais as pessoas com estomia ${ }^{8}$.

Distúrbios de imagem corporal são comuns em pessoas com estomia e, apesar de esses não dependerem de mudanças físicas para ocorrer, existe uma incidência maior em pessoas em pós-procedimentos mutiladores. A imagem corporal se caracteriza pela forma com que o indivíduo se enxerga; alterações nessas percepções interferem diretamente na autoestima, que é a avaliação global do indivíduo que se expressa pela aprovação ou desaprovação de si mesmo ${ }^{21}$.

Revisão integrativa ${ }^{22}$ referente às características definidoras de distúrbio de imagem corporal mostrou a presença significativa de distúrbio na imagem corporal em pessoas com estomias, especialmente em mulheres. As principais alterações observadas na literatura foram a mudança real na estrutura (100\%), relatos de percepções que refletem uma visão alterada na aparência do próprio corpo $(88,4 \%)$ e sentimentos negativos em relação ao corpo $(79,1 \%)$. Essas percepções negativas podem acarretar dificuldade para iniciar ou manter um relacionamento, pois o corpo passa a ser visto não apenas pela pessoa com estomia, mas também por seu companheiro ${ }^{18}$.

Quanto aos fatores demográficos, observa-se correlação significativa entre distúrbios de imagem corporal e idade, sendo que os mais jovens têm propensão maior a desenvolver distúrbio na imagem corporal. Isso pode ocorrer porque esses indivíduos estão mais envolvidos em atividades sociais em comparação com os mais velhos. A literatura também mostra taxa expressiva de depressão e ansiedade em pessoas com estomia, sendo que $43,9 \%$ dos 41 participantes do estudo apresentaram sintomas depressivos leves e $29,3 \%$ apresentaram sintomas leves de ansiedade. Da mesma forma, aqueles que apresentaram sintomas de depressão, ansiedade e pensamentos de autolesão apresentaram, também, maior comprometimento da imagem corporal $^{21,23}$.

No entanto, os fatores que contribuem para a má adaptação à alteração da imagem corporal não foram claramente estudados. É importante conhecer esses fatores, a fim de identificar aqueles que estão em maior risco de desenvolver distúrbios de imagem. Além disso, os fatores contribuintes modificáveis podem ser corrigidos para ajudar a melhor adaptação à imagem corporal ${ }^{23}$.

A aceitação da estomia se dá pela soma de estratégias de enfrentamento, e vários fatores influenciam positiva ou negativamente nesse processo adaptativo. Relacionamentos estáveis com envolvimento do parceiro no cuidado com a estomia têm influência positiva na percepção da imagem corporal. Ausência de comorbidades, apoio familiar, acesso a serviços de saúde e sentimentos esperançosos desempenham papel fundamental ${ }^{16,24}$.

A avaliação da percepção da imagem corporal da pessoa com estomia faz-se cada vez mais importante, pois o procedimento proporciona uma experiência diferente, com mudanças nos padrões até então vivenciados ${ }^{25}$. Ressalta-se a importância da atuação da equipe multiprofissional focada na reabilitação e na transição da forma mais natural possível. Recomendam-se a identificação dos fatores de risco para má adaptação no pré-operatório, realizar acompanhamento desses fatores no pós-operatório e nas consultas ambulatoriais ou visitas domiciliares, além da avaliação de sintomas depressivos e de ansiedade. É necessário conhecer e compreender esses fatores para planejar intervenções que ajudem a pessoa a lidar com suas novas características de forma tranquila e segura ${ }^{23}$.

Apesar da relevância dos dados encontrados, a pesquisa apresenta limitação, como o fato de ter sido desenvolvida em apenas uma instituição hospitalar e contado com número 
reduzido de participantes. Esse estudo permitiu visualizar os desdobramentos do cuidado, o processo de transição e os reflexos na imagem corporal de um grupo restrito, os participantes provenientes de uma única macrorregião que conta com serviço de apoio a pessoa com estomia relativamente bem estruturado. Recomenda-se que novos estudos sejam realizados, ampliando, assim, a população investigada e aprofundando o tema, com vistas a qualificar o cuidado e potencializar o processo de transição, buscando minimizar os distúrbios de imagem corporal.

\section{CONCLUSÕES}

O estudo permitiu observar as inúmeras modificações físicas, emocionais, sociais e no modo de viver das pessoas com estomia em seu processo de transição e adaptação, partindo de um diagnóstico sombrio, passando pelo procedimento cirúrgico mutilador, até a vivência com a estomia no domicilio e em sociedade. Observaram-se mudanças no padrão alimentar, no vestuário e no comportamento social, incluindo afastamento das atividades laborais e de lazer, além da presença de sentimentos e percepções negativas com relação ao corpo com estomia e novos desafios a serem vivenciados. Nesse contexto, as estratégias para o enfrentamento são de grande relevância. Observaram-se o apoio familiar, a religiosidade e a esperança da reconstrução do trânsito intestinal como fatores positivos nesse processo.

A condição de ser uma pessoa com estomia acarreta impacto na maneira como o indivíduo vê seu corpo. Observaram-se que esses procuram disfarçar aspectos do seu corpo que não lhes agradam, sentem-se menos atraentes fisicamente e mais inibidos, além de relatarem mudanças na vida sexual por dificuldade de aceitação e compreensão do novo corpo. Verificou-se adaptação mais favorável das pessoas com tempo maior de internação e que contaram com a presença de familiar, em especial o cônjuge, nos cuidados. As pessoas que permaneceram por mais tempo internadas em geral passaram por mais procedimentos cirúrgicos, necessidade de curativos e dispositivos invasivos, sendo a estomia um coadjuvante em uma experiência negativa. Já o envolvimento do cônjuge no cuidado a essa estomia fez os pacientes se sentirem mais seguros e aceitos com suas novas características.

Ressalta-se a importância de se identificarem os indivíduos com má adaptação o mais precocemente possível, para que sejam acompanhados pela psicologia e abordados quanto ao autocuidado. Todo o acompanhamento deve incluir as fases pré- e pós-cirúrgica, e também acompanhamento ambulatorial e domiciliar pela rede. A enfermagem tem amplo campo de atuação e intervenções no atendimento dessas pessoas, sendo que o enfermeiro pode potencializar a adaptação da pessoa com estomia à nova condição de vida e também promover reinserção social, por meio do acolhimento das demandas, apoio técnico humanizado e conhecimentos necessários para desenvolver potencialidades, como seu autocuidado e sua autonomia.

\section{CONTRIBUIÇÃO DOS AUTORES}

Conceitualização, Reisdorfer N e Locks MOH; Metodologia, Reisdorfer N e Locks MOH; Investigação, Reisdorfer N; Redação - Primeira versão, Reisdorfer N e Locks MOH; Redação - Revisão \& Edição, Reisdorfer N, Locks MOH, Girondi JBR, Amante LN1 e Corrêa MS; Recursos, Reisdorfer N e Locks MOH; Supervisão, Locks $\mathrm{MOH}$.

\section{REFERÊNCIAS}

1. Luz ALA, Luz MHBA, Antunes A, Oliveira GS, Andrade EMLR, Miranda SM. Perfil de los pacientes ostomizados: revisión integrativa de la literatura. Cul Cuid. 2014;18(39):115-23. https://doi.org/10.7184/cuid.2014.39.13

2. Mota MS, Gomes GC, Petuco VM. Repercussions in the living process of people with stomas. Texto Contexto Enferm. 2016;25(1):e1260014. https://doi.org/10.1590/0104070720160001260014

3. Schilder P. A imagem do corpo: as energias construtivas da psique. São Paulo: Martins Fontes; 1981.
4. Marques SG, Nascimento DC, Rodrigues FR, Lima CMF, Jesus DF. A vivência de pessoas com estomia intestinal no grupo de apoio em um Hospital Universitário. Revista HUPE. 2016;15(2):11321. https://doi.org/10.12957/rhupe.2016.28235

5. Ministério de Saúde. Conselho Nacional de Saúde (BR). Resolução n 466 de 12 de dezembro de 2012. Diário Oficial da União. Pag. 59.

6. Tapadinhas AR, Palhinhas P, Gouveia P. Validação da escala de imagem corporal "como me relaciono com o meu corpo": estudo com uma amostra de mulheres com cancro 
da mama. Actas do $6^{\circ}$ Congresso Nacional de Psicologia da Saúde Lisboa; Lisboa, Portugal. Instituto Superior de Psicologia Aplicada Edições; 2006.

7. MINAYO M. C. S. O desafio do conhecimento: pesquisa qualitativa em saúde. São Paulo: Hucitec; 2013.

8. Barbosa MH, Poggetto MTD, Barichello E, Cunha DF, Silva R, Alves PIC, et al. Aspectos clínicos e epidemiológicos de estomizados intestinais de um município de Minas Gerais. REAS. 2014:3(1):64-73.

9. Moraes JT, Assunção RS, Sá FS, Lessa ER, Corrêa LS. Perfil de pessoas estomizadas de uma região de saúde mineira. Enferm Foco. 2016;7(2):22-6. https://doi. org/10.21675/2357-707X.2016.v7.n2.788

10. Miranda SM, Luz MHBA, Sonobe HM, Andrade EMLR, Moura ECC. Caracterização sociodemográfica e clínica de pessoas com estomia em Teresina. ESTIMA, Braz J Enterostomal Ther. 2016;14(1):29-35. https://doi.org/10.5327/Z18063144201600010005

11. Aguiar JC, Pereira APS, Galisteu KJ, Lourenção LG, Pinto $\mathrm{MH}$. Clinical and sociodemographic aspects of people with a temporary intestinal stoma. Rev Min Enferm. 2017;21:e1013. https://doi.org/10.5935/1415-2762.20170023

12. Barbosa MR, Simon BS, Tier CG, Garcia RP, Siniak DS, Rodrigues SO. Perfil de pessoas com estomias de um serviço de saúde municipal no Sul do Brasil. ESTIMA, Braz. J. Enterostomal Ther. 2018;16:e-1318. https://doi. org/10.30886/estima.v16.465_PT

13. Freitas JPC, Borges EL, Bodevan EC. Caracterização da clientela e avaliação de serviço de atenção à saúde da pessoa com estomia de eliminação. ESTIMA, Braz. J. Enterostomal Ther. 2018;16:e-0918. https://doi.org/10.30886/estima. v16.402_PT

14. Queiroz CG, Freitas LS, Medeiros LP, Melo MDM, Andrade RS, Costa IKF. Caracterização dos ileostomizados atendidos em um serviço de referência de ostomizados. Enferm glob. 2017;16(46):13-24. https://doi.org/10.6018/ eglobal.16.2.230551

15. Ribeiro RVL, Oliveira AC, Viana LVM, Pinto AP, Carvalho ML, Elias CMV. Adaptação social do paciente colostomizado: desafios na assistência de enfermagem. R Interd. 2016;9(2):216-22.
16. Baykara ZG, Demir SG, Karadag UM, Harputlu D, Kahraman UM, Karadag $S$, et al. A multicenter, retrospective study to evaluate the effect of preoperative stoma site marking on stomal and peristomal complications. Ostomy Wound Manage. 2014; 60(5):16-26.

17. Azevedo C, Faleiro JC, Ferreira MA, Oliveira SP, Mata LRF, Carvalho EC. Intervenções de enfermagem para alta de paciente com estomia intestinal: revisão integrativa. Rev Cuba Enferm. 2015;30(2).

18. Lima RA, Paulino EFR, Silva VMR, Loureiro AAS. Analisando produções científicas acerca da educação do enfermeiro estomaterapeuta na última década do século XXI. Rev Enferm Prof. 2014;1(2):462-70.

19. Mota MS, Gomes GC, Petuco VM, Heck RM, Barros EJL, Gomes VLO. Facilitadores do processo de transição para - autocuidado da pessoa com estoma: subsídios para Enfermagem. Rev Esc Enferm USP. 2015;49(1):82-8. https:// doi.org/10.1590/S0080-623420150000100011

20. Silva CRDT, Andrade EMLR, Luz MHBA, Andrade JX, Silva GRF. Quality of life of people with intestinal stomas. Acta Paul Enferm. 2017;30(2):144-51. https://doi.org/10.1590/1982-0194201700023

21. Hong KS, Oh B, Kim E, Chung SS, Kim KH, Lee R. Psychological attitude to self-appraisal of stoma patients: prospective observation of stoma duration effect to self-appraisal. Ann Surg Treat Res. 2014;86(3):152-60. https://doi.org/10.4174 \%2Fastr.2014.86.3.152

22. Costa IKF, Liberato SMD, Freitas LS, Melo MDM, Sena JF, Medeiros LP. Distúrbio na imagem corporal: diagnóstico de enfermagem e características definidoras em pessoas ostomizadas. Aquichan. 2017;17(3):270-83. https://doi. org/10.5294/aqui.2017.17.3.4

23. Jayarajah U, Samarasekera DN. Psychological adaptation to alteration of body image among stoma patients: a descriptive study. Indian J Psychol Med. 2017;39(1):63-8. https://doi.org/10.4103/0253-7176.198944

24. Aktas D, Gocman BZ. Body image perceptions of persons with a stoma and their partners: a descriptive, crosssectional study. Ostomy Wound Manage. 2015;61:26-40.

25. Salomé GM, Almeida SA, Silveira MM. Quality of life and self-esteem of patients with intestinal stoma. J Coloproctol. 2014;34(4):231-9. https://doi.org/10.1016/j.jcol.2014.05.009 